\title{
The Casting of American and Chinese Sitcoms From the 1950s to the 2010s
}

\author{
Jinyuan Zheng \\ Shanghai United International School Pudong Campus, Shanghai, 200126, China \\ Corresponding author's e-mail: angela@cas-harbour.org
}

\begin{abstract}
Sitcoms production teams often choose actors with unique styles. Longevity of actors' performance and versatility are two major qualities that the sitcom actor should maintain [2]. Old actors are experienced, while the new actors can bring up the spirit of contemporary society. Therefore, both kinds of actors are required for sitcoms. Different departments in the production team all support actors to deliver the purpose of the sitcom to the audience. Directors help to form the character and select suitable actors under auditions and feelings. Cinematographer Cameraman uses the Three Lens Model and the dolly shot to exaggerate the detail performance of the actors with the demonstration of I love Lucy and the Big Bang theory. Costume and makeup help to deliver the historical background and better the looking of characters in the screen with examples from happy days. The use of Laff Box brings tremendous benefits for the sitcoms. The relationships between actors and audience are gradually closer as the century and technology developed, this can be seen from the Chinese sitcom apartment. Other sitcoms such as growing pains, friends and the Hank McCune show are useful to clarify the findings and ideas in this paper as well. The findings can be used for the director to make a successful sitcom with suitable actors.
\end{abstract}

Keywords: Actors, sitcoms, popularity, Chinese sitcoms, history

\section{INTRODUCTION}

The topic of this research is to find out the background and rationale of the casting for the early age family and friend sitcom genre from the 1950 s to today from several perspectives. Sitcoms are made mostly for entertainment purposes and reflect a real society's life on the screen. [1]Actors play the most significant part in these performances; they are the ones who directly deliver the messages to the audience. Therefore, it is important to find out what kind of actors are suitable for the play, and who can handle the right pace and deliver the right emotions to the audience, and leading them to laugh at the right point. Each episode is about half an hour-long, and each episode has an independent story with an individual ending. Also, look back to those early sitcoms, such as I love Lucy in the 1950s, it can let the reader understand if there is any difference in selecting actors that time and nowadays such as the Big Bang theory. What is the difference between actors acting in the sitcoms and normal TV series? How do the different departments of film production including camera angles, costumes, etc. help the actors to successfully deliver the message? The reason why this topic is worthy of being researched is that it may provide better recommendations and suggestions for sitcom directors to select the most suitable actors for their shows in the future.

\section{New actors VS. Old actors}

\subsection{Style and quality of actors}

Actors are the most significant factor for a successful sitcom. Each actor needs to have their styles and specialties to let the audience remember them. There are several qualities that all the sitcom actors should have. Some qualities are especially crucial.

First of all, all actors should have believability, versatility and a good communication skill. The performance of the actors should be convincing. That requests them to believe in their characters and regard themselves as the character in order to bring up the most realistic character in front of the audience. A great performance can make the audience forget that they are looking at an actor performing a role, the audience will believe that the characters are real persons in life. If actors do not trust their characters and the stories, why should the audience trust it? Based on versatility, all actors should have the ability to act out any kinds of the characters that the production team requires, the character can be completely different from the actors themselves or their previous character. Also, the sitcom actors should have a great ability to listen and respond, because all characters need to interact with each other, whether in pace or behaviors. In this way, actors must listen to others carefully and deliver the most realistic response when it comes to their turn. 
Secondly, longevity of actors' performance is a very significant quality for all the actors, especially for the sitcom actors. Sitcoms normally have more than one season, in other words all the actors will be needed for all the seasons. It is very hard to change any actors in the middle of the season, because it is highly possible to lose the audience. Therefore, actors need to sustain a quality of excellence over a long time. Actors must be reliable and responsible as well. Before every production starts to shoot, it requires a large amount of work beforehand. Such as, the director and producer need to write out the whole story and go through many times to make sure it is the best version. After that, they need to gather all different departments for discussion and cooperation. Until everything's prepared, then the actors will be needed for shooting. Therefore, actors must be very responsible and reliable to accomplish their work in high quality.

\subsection{Different Preparations for New and Old Actors}

There are a few crucial steps that all the actors need to do before acting in sitcoms, even other plays. However, the difference between the old and new actors can only be seen through the time it has taken for them to complete each step. For example, in a Chinese sitcom called apartment, in the last season, the director added three new actors into the sitcoms. [6] Compare to those actors who has been acting in this show for 10 years. The different preparations they need to do are very obvious. First of all, all actors need to read the play many times and deep reading, to understand the plot and the relationship between the characters. For the old actors, the only thing they need to do is to read the content, because they are familiar with their characters and clearly know the relationship they have with others. For the newer actors, besides reading the content they also need to pay more thoughts into understanding their relationships with others in order to deliver the right message to the audience.

After all the actors are familiar with their scripts, the next thing they need to do is to memorize their lines. Old actors have much more experience in memorizing their scripts, and they know how their characters will act out the lines with their particular styles. This may be a challenge steps for the new actors, because they also need to think of a way of speaking that represents their characters' style. Also, they are more focused on their pronunciation and the pace when acting in the sitcoms. Pace is a very important factor for a successful sitcom because all the audience are following actors' pace of emotions, if they say the words too fast, it may be difficult for the audience to catch up actors' words and emotions, on the other hand, if they say it too slow, the audiences may get a bit bored of their performance. Therefore, new actors are always practicing their pace and pronunciation to achieve the required accuracy.

The last step is rehearsal and is ready to act. Normally old actors have a better rapport with each other, therefore it may take less time for them to rehearse with each other in a relaxed mood. However, for the new actors, they may get much more nervous when rehearsing, under nervous mood it is possible for them to make mistakes that would consume much more time in the rehearsal. Moreover, at the beginning of the rehearsal, new actors are less familiar with their characters. [3] In this case, it much more likely that they require more time for rehearsal.

\section{Cooperation between different departments of film production with the actor}

\subsection{Selection and cooperation with Directors}

Directors love to use old characters but are also willing to discover talented new actors for creating young characters in the sitcom. As the centuries are developing, the spirit, feeling, thoughts, and view of life and values brought by new actors and old actors can be different. Characters can be any individuals in the society, therefore old actors are more experienced and familiar with their acting. On the other hand, as more youngsters are interested in watching sitcoms, directors also designed new and young characters that required new actors for performance due to the freshness and ambitious that new actors have. It can let the younger audience see and reflect themselves on those characters and to have a stronger sense of substitution and empathy with the character.

Directors are often the ones who mainly decide which actors they are going to use for their sitcoms. The most common way of the audition is to let the actors act out one scene from the script. It will give a better idea for the directors to decide the most suitable actors for their characters. For example, in the Chinese sitcom apartment, all actors are asked to act out one scene of their characters in front of the director and producers. [6] However, there are also some other ways of the audition. For example, in the American sitcom growing pains shot in the 1990s, the director and the interviewer asked the young actors to tell a story. It was a fierce competition for an 8 years old younger son Ben. Jeremy miller competed with more than 400 children and got the character by his high voice and stood out to be the right person for Ben. Before the audition, most directors already have an expectation of the actors that they are looking for. [4] For instance, in ipartment, the main character is a very extroverted woman with high volume voice, the actor Lou Yixiao went for the audition, when she acted out the scene with her thoughts of the character, it exactly matched the expectation of the director and successfully made the interviewer laugh. [6] Therefore, directors and interviewers often want actors who have the most similarities and have a good understanding of the characters, also when they are acting, it should make people believe in the character, actors are no longer themselves. Another major factor that affects the director to make their final decisions is the feeling they have of the actor. Most importantly, the interviewers are looking for the unique style that the sitcom actors have and value the suitableness for their sitcoms. Also, directors are 
willing to see how can the actor act out the comedy part with natural performance but can make audience laugh a lot. Actors need to prepare forehand before they start shooting, directors are also the guidance for them to have better performance. For all the directors, they know clearly about the scope of the actors and their abilities, therefore directors will push the actors to act with their maximum ability. First of all, the director helps the actors to pace their performance, including their speaking speed and movements that match their characters. Moreover, the director will give a much more detailed description of the characters for the actors to have a much better understanding, especially when the director is looking for some kinds of the spirits or mood that the character needs to deliver. When the actors are very struggling for some scenes, the director will demonstrate and correct their mistake, in order to let them know under which word or lines need to give what kind of reaction.

\subsection{Director of the photography (DP) or Cinematographer Cameraman \& Lighting Engineer}

I love Lucy was the first successful situation comedy shot in the $1950 \mathrm{~s}$ and made a large impact on later generations. It used a newly invented shooting model throughout the whole show, which is called Three Lens Model, which was designed by a famous Hollywood photographer Karl Freund. He originally invented Dolly shot, the most common shooting strategy that the director of the photograph uses when filming a moving object or actor. Then it developed into Three Lens Model. Three Lens Model is referred to place three cameras at the left, middle and right parts of the scene respectively. During actors' performance, three cameras film at the same time. The middle camera is responsible for the panoramic view, which normally captures more than one actor in the picture and gives the message of the scene to the audience. To tell the audience specifically where is the scene happening and who is there involving. Cameras on the left and right sides are responsible for the close-up shots, they concentrate on actors' body language and delivers different messages from their facial expressions or small movements. In this way, it gives the audience a much more clear view of what the actor is trying to express in different scenes. Three Lens Model was a great development as it can avoid repeated shooting for the same scene but for different angles, which can reduce the working pressure of the crew to the greatest extent and save a lot of time and cost for the film production. Till now, the model is still used in the sitcoms, such as the Big Bang theory and friends, even influenced Chinese sitcoms in shooting skills. [5] In the newest produced Chinese sitcom apartment, they also used a full-length shot to film their musical parts. This kind of shooting strategy connects all different scenes together smoothly and involved all characters to be in one shot.

\subsection{Makeup \& Costume Design}

Costume and makeup are the most direct message it delivers to the audience. The costume suggests which era or what kind of atmosphere the characters are in, makeups often give actors better looking on the TV. Costumes in the sitcoms are more life-like dressing as the setting is in everyday life, but when it comes to certain festivals or parties with theme, their costumes are much more ridiculous and odd that will make people laugh about it. For instance, the first episode of 'I Love Lucy', Lucy dressed up like an ugly woman, when people first saw her costume it seems very strange but interesting. Moreover, the sitcom happy days was shot in the 1970s. However, the plot is about stories that happened in the 1950s Besides the music pertains to the $1950 \mathrm{~s}$, the costume department also worked on characters' costume, in order to bring the audience into the scene and believe this is a 1950s' sitcom. In the happy days' girls wear dresses with a tight belt on their waists and boys wear baseball uniforms. Moreover, the costume also helps the sitcom to deliver the message of unconscious sexism and heterosexual of the 1950s.

The Chinese sitcom apartment is about 7 youngsters living in two apartments and how they build up different relationships with each other. In almost every episodes, characters wear funny animal pyjamas especially during the morning and evening, it creates a sense of home and reflects the real side of daily life. In addition. there are some couples in the scene as well. When they put on costumes like couple T-shirts, it can directly tell the audience the relationship between the characters, even if they did not watch other episodes before. Moreover, in the sitcoms, every character has their own identities, styles, and job. As a university student, she normally has casual wear and the color of her costume is brighter and more colorful than others as it represents the youthful spirit. In contrary, for a man whose job is a lawyer, in most scenes, he wears a business suit with ties. Therefore, costumes and makeups are really useful for the characters to emphasize their style and identity in the sitcoms.

\section{The relationship with the audience}

\subsection{The function of Laugh box}

Based on psychological research, it has found that the principle of humor and willingness to laugh is caused by dissonance, which is when you are finding something abnormal. At the same time, you understand and know why they are performing abnormal, in this way, people want to laugh with it. [7] The laughing box is a very crucial part of the sitcom, it usually helps the actors to deliver the laugh points to the audience and sends out different levels of laughing at distinct scenes. The psychological basis behind the laughing box is that human society approves of spontaneous imitation. When others laugh, the audiences 
surround are more inclined to laugh as well. This unconscious imitation is not controlled by people's supervisors. It is a kind of conditioned spontaneous behavior. In this way, it creates a better atmosphere for the sitcoms. The first laughing box was called 'canned laughter', it was used in the Hank McCune show in the 1950s. [5][8]

However, when filming the show with the real audience's laugh, it required the show to start over 3 to 4 times just for different shooting angles. Therefore, the audience gets tired of laughing, so the outcome was not very successful. Later, a sound engineer Charley Douglass raised an idea to sweeten the laughter, which is to add the recorded laughter to the desired track, and named the laughter Laff BOX. Inside the Laff BOX, it contains tapes of many different kinds of laughter that were collected from a sitcom called "The red Skeleton Show". The laughing box improved the efficiency of sitcoms production and also gets more audience to laugh with it. While it satisfies more audiences, it boosts a better rating for the sitcoms. Moreover, on an ideological level, the Laff Box helps to justify and makes sense of the content and has positive reinforcement. It may help the audience to distinguish the abnormal and normal from the laughter. The sense is built by the others around the audience, when the audience is not the only one who finds the scene interesting, It creates the consensus for the audience, because people are fearful of missing out (FOMO), they want to be a part of the flock. If everyone's laughing including audience themselves, they feel inclusiveness.

\subsection{Purpose and Message of Sitcoms}

Sitcoms do not often carry out a big message of truth for the audience to learn, instead, the main purpose of the sitcoms is to deliver positive attitudes and happiness to the audience. The format of the sitcoms is very suitable for those who want to have relaxed with some happiness in everyday life. All the characters in the sitcom are common individuals that ordinary people can meet in daily life, for each episode they may face a difficulties that the audience may meet as well, however, the story ends for each episode and start a new one for the next episode, the spirit it wants to deliver to the audience is that all difficulties will past. Sitcoms can let people forget about unhappiness, be encouraged and believe in that life is still worthy and intriguing.

\subsection{Interconnection With the Audience}

Sitcoms deliver happiness for the audience. Meanwhile, audiences are the one who drives the sitcoms to continue till today. In the past, the way audiences gives ideas or opinions was through the conversation with people surrounds them. There was not a very professional website that provides audiences the platform to share their comments and rates. As the technology developed in the past few decades, it can actually closely connect the sitcoms and their audience. For western audience, they can use IMDB or some other platforms to rate, send the comments they have for each
Ssitcom they watched and they can also use social networking software such as Instagram, Facebook, etc for recommendation and encourage more people to watch the really good ones. In China, the audience mainly use a platform called Douban to rate and counted it as the most official data, but the audience can also use software like Weibo to comment and communicate with other audiences to share their thoughts.

Till now, social software are no longer one direction communication, it also provides a channel for the production team and actors to communicate with their audience and understand their expectations and desire from the sitcoms. For instance, before apartment started to shoot the final season, they made a film with roadshows to each city. In every roadshow, besides the interaction, the audience can have with the actors. The audience also got the opportunity to speak and share the thoughts they have. Also, they can talk about what kinds of scenes they were expected but have not seen in the film or past few seasons. The production team cares a lot about the audience's expectations and wishing the final season can bring them a happy ending. [6] Actors are also willing to give the best performance in the final season to satisfy the audience who accompanied them for ten years. They opened up a topic in Weibo, where all users and audiences are free to send any thoughts and will they have for the final season which may be adopted. They can also directly send the message to the director or the production team with their ideas. Later, when the production team is building up the script and story, they do communicate with the actors, take the advice from the audience and also set some episodes with audiences involved. For example, in one episode of apartment, the topic is about bullet subtitles. Those were all the comments that the audience has on the characters when they are watching the sitcoms. In that episode, the audience can determine the direction and plot of the story and also see how the characters will react distinctively to both negative and positive feedback in order to recognize the severity of cyberbully. Another episode laughter in my heart is very close to the ending. Therefore the production team shot a full episode with real audiences sitting in the scene. When they stopped laughing at the usual jokes that the characters make, it is really strange for the characters and also brings them into a very sad mood. In this episode, the director wants to thanks the audiences for their accompany during the last ten years, and let them understand that apartment would not be happy without them. However, it also wants to tell the audience to not be sad when it is the real ending. They should live with the positive spirit of ipartment and let the happiness stay. [6]

\section{SUGGESTION}

To select the most suitable actors, directors must choose the actors with their unique style and have the ability to create laugh point through their acting that will make the audience remember the character. Also, the production team should carefully value the quality of the actors. Especially in the longevity of actors' performance, as the 
sitcom usually have more than one season need to produce. Moreover, directors should be encouraged to use new actors and younger actors. Because as society developed, more younger audiences are willing to watch sitcoms, so the production team must set a young character or two that younger audiences feel familiar and understandable with, to create empathy and freshness. This can also boost the rate of sitcoms because young people are the majority of individuals who are willing to relax under severe pressure and also when they find out that characters in the sitcom seems so familiar and close to them, it will attracts more youngsters to watch. To be a successful sitcom actor, they must have a great ability to listen and respond to their partners, good cooperation can handle the right pace of the story, in this way it is much easier to create a relaxing atmosphere which delivers happiness and the laugh point. The stereotype that was brought by old actors should not be a problem for them to adopt the new sitcom. All professional actors should be versatile and believe in their character, therefore whenever they act, they should let the audience to remember the character instead of themselves.

\section{CONCLUSION}

Sitcom actors have their unique styles that make the audience remember them and their major qualities are versatility and longevity. To determine a good actor requires the director to have an audition with them acting out a real scene from the script with their understanding of the character and the way to deliver the laugh point to the audience. Meanwhile, before the audition, directors should have an expectation of what kinds of personalities and styles they want for their characters and also the feeling that the director has of the actor is very important. It is a great idea to discover new talented actors for the sitcoms as they may attract the attention of the youngsters in society. It is necessary to consider the hardness of finding materials about casting of early sitcoms. Later, it is worthy to look forward to comparing the casting in American and Chinese sitcoms.

\section{ACKNOWLEDGMENT}

First and foremost, I would like to show my deepest gratitude to my teachers and professors in my high school, who have provided me with valuable guidance in every stage of the writing of this thesis. Further, I would like to thank all my friends and family for their encouragement and support. Without all their enlightening instruction and impressive kindness, I could not have completed my thesis.

\section{REFERENCES}

[1] W. F. Metz, How sitcoms Work: Sitcom Characteristics, Website how stuff works https://entertainment.howstuffworks.com/sitcom3.htm, $(2008 / 02 / 05)$, accessed on $(2020 / 02 / 21)$

[2] What are the qualities that make a good actor?, Website Broadway World, https://www.broadwayworld.com/board/readmessage. php?thread $=969203$ \&boardid $=2$, accessed on $(2020 / 02 / 29)$

[3] P. Mroczka, An Actor Must Prepare: A Checklist for Student, Website Broadway Educator, http://broadwayeducators.com/an-actor-must-preparea-checklist-for-student-actors/ (2014/07/10), accessed on $(2020 / 03 / 05)$

[4] Zhang Shi Ba Xian, You must be aware of the 'Growing pains' casting process, WeChat Official Account: Zhui Ying $\mathrm{Bu} \mathrm{Yu} \mathrm{Yu} \mathrm{Wei} \mathrm{Yang,}$ https://baijiahao.baidu.com/s?id=1561360714827769 $\& w f r=$ spider\&for $=p c, \quad(2017 / 03 / 09), \quad$ accessed on $(2020 / 03 / 06)$

[5] North Park Wang Xiaoben, How did American sitcoms get to where they are today, Website Huxiu, https://www.huxiu.com/article/299896.html, $(2019 / 05 / 18)$, accessed on $(2020 / 02 / 29)$

[6] Z.Wei. Special Edition for Goodbye Ipartment : EP01 'To be Innovative', https://www.iqiyi.com/v_19rw7vue7g.html, (2020/01/14), accessed on (2020/03.07) ; EP03 'Selfcultivation of a comedian (1)', https://www.iqiyi.com/v_19rw5mepsw.html, (2020/01/23), accessed on (2020/03/07) ; EP04 'Selfcultivation of a comedian (2)', https://www.iqiyi.com/v_19rw5meq7o.html, (2020/01/24), accessed on (2020/03/07) ; EP05 'Bye, we are done', http://m.iqiyi.com/v_19rw1jbvic.html?key=b398b8ccb aeacca840073a7ee9b7e7e6\&msrc=3_31_56\&aid=122 $84636200 \&$ tvid $=12284636200 \&$ cid $=10 \&$ identifier $=\mathrm{W}$ eixinv $1 \&$ ftype $=27 \&$ subtype $=1 \&$ vip_pc $=0 \&$ vip_tpc $=0$ $\&$ isrd $=1 \& p 1=2 \_22 \_222 \&$ social_platform=link, $(2020 / 02 / 11)$, accessed on $(2020 / 03 / 07)$; EP07 'Remain True to our original Aspiration', http://m.iqiyi.com/v_19rvn9sp34.html?key=b398b8cc baeacca840073a7ee9b7e7e6\&msrc $=3$ 31_56\&aid $=12$ $491809900 \&$ tvid $=12491809900 \& \mathrm{cid}=10 \&$ identifier $=$ weixinv $1 \&$ ftype $=27 \&$ subtype $=1 \&$ vip_pc $=0 \& v i p \_t p c=$ $0 \&$ isrd=1\&p1=2_22_222\&social_platform=link, 
(2020/02/10), accessed on $(2020 / 03 / 07)$; Interview of Director Wei Zheng: 'I owe audience an ending', $\mathrm{http}: / / \mathrm{m}$.iqiyi.com/v_19rw51678o.html?key=b398b8ccbae acca840073a7ee9b7e7e6\&msrc $=3$ _31_56\&aid $=1145169$ $2100 \&$ tvid $=11451692100 \&$ cid $=10 \&$ identifier $=$ weixinv 1 $\&$ ftype $=27 \&$ subtype $=1 \& v i p \_p c=0 \& v i p \_t p c=0 \& i s r d=1 \&$ p1=2_22_222\&social_platform=link, $\quad(2020 / 01 / 16)$, accessed on $(2020 / 03 / 07)$
[7] Huge. What is the scientific basis for canned laughter in sitcoms. Website Zhihu, https://www.zhihu.com/question/20606668, (2014/02/21), accessed on (2020/02/29)

[8] Hutengfei. Why there are laughter in the sitcom, Website Zhihu, https://www.zhihu.com/question/29316263, (2015/06/13), accessed on (2020/02/29) 